\title{
Neonatal seizures and postneonatal epilepsy: a 7-y follow-up study
}

\author{
Francesco Pisani', Benedetta Piccolo', Gaetano Cantalupo', Cristiana Copioli', Carlo Fusco², Annalisa Pelosi³, \\ Carlo Alberto Tassinari ${ }^{4}$ and Stefano Seri ${ }^{5,6}$
}

BACKGROUND: Seizures are one of the most common symptoms of acute neurological disorders in newborns. This study aimed at evaluating predictors of epilepsy in newborns with neonatal seizures.

METHODS: We recruited consecutively 85 neonates with repeated neonatal video-electroencephalogram (EEG)confirmed seizures between January 1999 and December 2004. The relationship between clinical, EEG, and ultrasound (US) data in the neonatal period and the development of postneonatal epilepsy was investigated at $7 \mathrm{y}$ of age.

RESULTS: Fifteen patients (17.6\%) developed postneonatal epilepsy. Partial or no response to anticonvulsant therapy (odds ratio (OR) 16.7, 95\% confidence interval (Cl): 1.8-155.8, $P=0.01$; OR 47, 95\% Cl: 5.2-418.1, $P<0.01$, respectively), severely abnormal cerebral US scan findings (OR: 5.4; 95\% Cl: 1.1-27.4; $P<$ 0.04), severely abnormal EEG background activity (OR: $9.5 ; 95 \%$ $\mathrm{Cl}: 1.6-54.2 ; P=0.01$ ), and the presence of status epilepticus (OR: $6.1 ; 95 \% \mathrm{Cl}: 1.8-20.3 ; P<0.01$ ) were found to be predictors of epilepsy. However, only the response to therapy seemed to be an independent predictor of postneonatal epilepsy.

CONCLUSION: Neonatal seizures seem to be related to postneonatal epilepsy. Recurrent and prolonged neonatal seizures may act on an epileptogenic substrate, causing further damage, which is responsible for the subsequent clinical expression of epilepsy.

$\mathbf{S}^{\mathrm{s}}$ eizures are one of the most common symptoms of acute neurological diseases in newborns and their incidence is considerably higher during the neonatal period than at any other time of life (1). Current estimates indicate a prevalence of neonatal seizures ranging from $0.5 \%$ in full-term newborns to $22.2 \%$ in preterm newborns (2). Neonatal seizures represent a common neurological sign in the neonatal intensive care unit (NICU) and are associated with increased risk of death as well as of long-term morbidity in survivors, including mental retardation and postneonatal epilepsy (3).

The most frequent etiologies of acute brain injury in the perinatal period are hypoxic-ischemic encephalopathy in full-term newborns and cerebral hemorrhage in preterm infants, often resulting in long-term neurological sequelae such as cerebral palsy (CP), mental retardation, and in $\sim 17$ $56 \%$ of patients, epilepsy (4). Perinatal brain damage and/ or neonatal seizures can be risk factors for developing epilepsy in later years (2). A recent study reports that $\sim 16 \%$ of patients with neonatal seizures die early, whereas $33 \%$ have an adverse outcome (3).

Experimental studies in animals show that the immature central nervous system is more susceptible to developing seizures secondary to brain damage than that of adult animals, although the immature brain is less susceptible to damage induced by seizures $(5,6)$.

An association between factors responsible for neonatal brain injury and development of epilepsy in childhood has been reported. However, published data on the magnitude of the risk of developing postneonatal epilepsy and predisposing factors present considerable variability mainly due to small sample size of some studies, inclusion of newborns with seizures detected only clinically, and short follow-up duration $(3,7,8)$. We attempted to address this gap by evaluating the frequency of postneonatal epilepsy at $7 \mathrm{y}$ of age in a group of patients who presented video-electroencephalogram (EEG)confirmed neonatal seizures and evaluated the clinical, EEG, and cerebral ultrasound (US) findings associated with the development of epilepsy.

\section{RESULTS}

Between January 1999 and December 2004, of the 2,072 newborns consecutively admitted at the NICU of the University of Parma, 85 (4.1\%) presented video-EEG-confirmed neonatal seizures and fulfilled our inclusion criteria. Mean gestational age (GA) was 34.38 (SD 5.9) and birth weight ranged between $500 \mathrm{~g}$ and $4,450 \mathrm{~g}$ (mean birth weight 2,283 g, SD 1,174.8). Mean follow-up was 8.6 y (SD 1.5) with a minimum of $7 \mathrm{y}$; no patient was lost to follow-up. The characteristics of the sample and clinical findings are summarized in Table 1.

At least one probable etiology was identified in all newborns and the most frequent was hypoxic-ischemic encephalopathy (43.5\%). In all patients, postnatal computed tomography or

${ }^{1}$ Child Neuropsychiatry Unit, Department of Gynecology, Obstetrics and Neonatology, University Hospital of Parma, Parma, Italy; ${ }^{2}$ Pediatric Neurology Unit, Arcispedale Santa Maria Nuova, Reggio Emilia, Italy; ${ }^{3}$ Psychology Department, University of Parma, Parma, Italy; ${ }^{4}$ Neuroscience Department, University of Parma, Parma, Italy; ${ }^{5}$ School of Life and Health Sciences, Aston Brain Centre, Aston University, Birmingham, UK; ${ }^{6}$ Department of Clinical Neurophysiology, The Birmingham Children's Hospital NHS Foundation Trust, Birmingham, UK. Correspondence: Francesco Pisani (francesco.pisani@unipr.it) 
Table 1. Sample findings

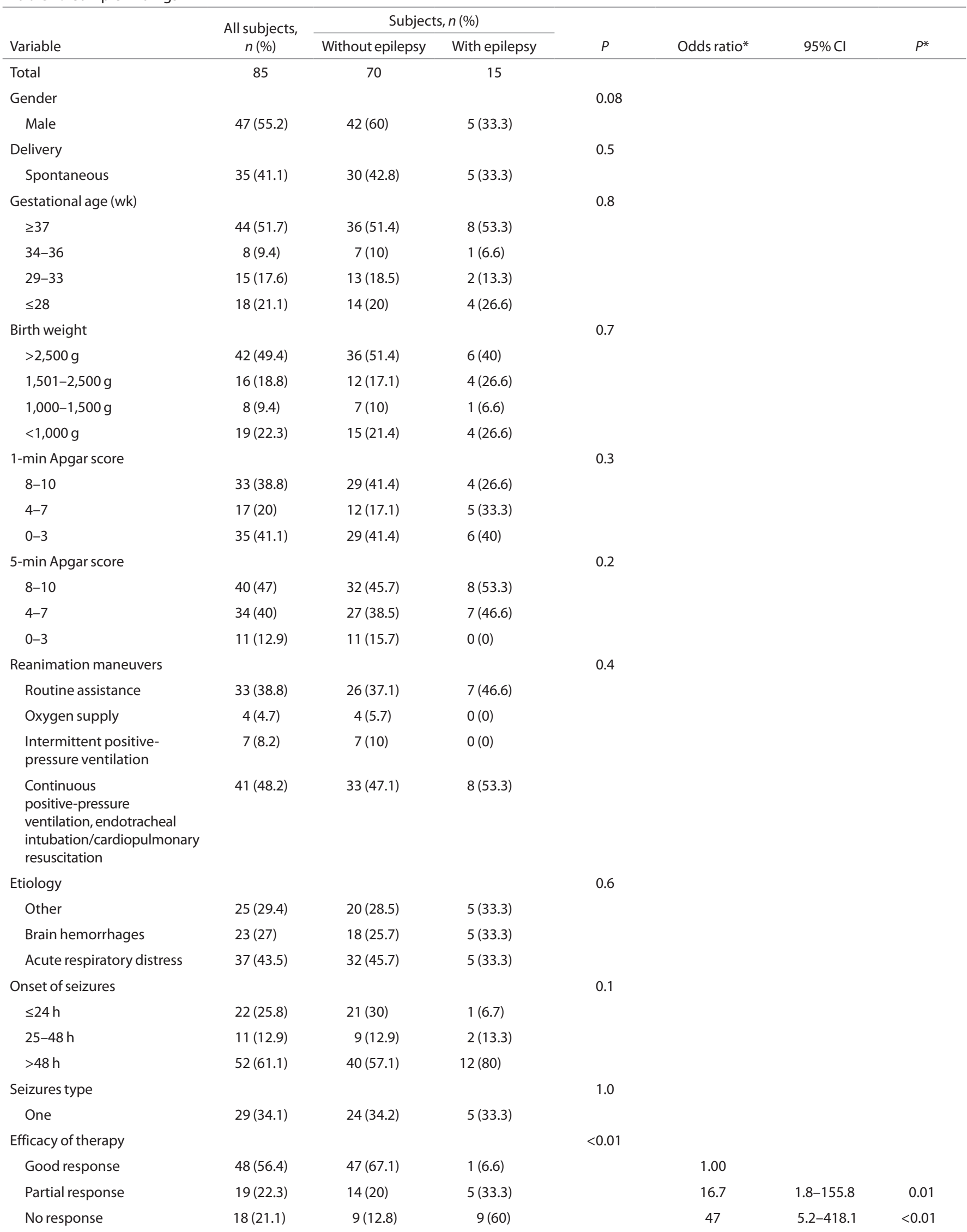

Table 1. Continued on following page 
Table 1. Continued

\begin{tabular}{|c|c|c|c|c|c|c|c|}
\hline \multirow[b]{2}{*}{ Variable } & \multirow{2}{*}{$\begin{array}{c}\text { All subjects, } \\
n(\%)\end{array}$} & \multicolumn{2}{|c|}{ Subjects, $n(\%)$} & \multirow[b]{2}{*}{$P$} & \multirow[b]{2}{*}{ Odds ratio* } & \multirow[b]{2}{*}{$95 \% \mathrm{Cl}$} & \multirow[b]{2}{*}{$P^{*}$} \\
\hline & & Without epilepsy & With epilepsy & & & & \\
\hline Ultrasound brain scans & & & & $<0.01$ & & & \\
\hline$\|^{a}$ & $27(31.7)$ & $26(37.1)$ & $1(6.6)$ & & 0.4 & $0.03-4.7$ & 0.4 \\
\hline $11 \mathrm{I}^{\mathrm{b}}$ & $35(41.1)$ & $23(32.8)$ & $12(80)$ & & 5.48 & $1.1-27.4$ & 0.04 \\
\hline Moderately abnormal & $31(36.4)$ & $24(34.2)$ & $7(46.6)$ & & 5.1 & $0.9-26.7$ & 0.054 \\
\hline Severely abnormal & $17(20)$ & $11(15.7)$ & $6(40)$ & & 9.5 & $1.6-54.2$ & 0.01 \\
\hline Neurological examination & & & & 0.3 & & & \\
\hline Normal & $36(42.3)$ & $32(45.7)$ & $4(26.6)$ & & & & \\
\hline Yes & $19(22.3)$ & $11(15.7)$ & $8(53.3)$ & & 6.1 & $1.8-20.3$ & $<0.01$ \\
\hline
\end{tabular}

magnetic resonance imaging confirmed the neonatal cerebral US findings. Etiology was not related to epilepsy $(P=0.6)$. Furthermore, the majority of newborns (61.2\%) presented a seizure onset after the first $48 \mathrm{~h}$ of life and more than one type of seizure (65.9\%). Focal/multifocal clonic was the most frequently observed seizure type.

\section{Normal vs. Adverse Outcome}

A favorable outcome was seen in 33/85 infants (38.8\%) and an adverse outcome in 52 . Fifteen of those with adverse outcomes died. Twenty-seven patients $(31.7 \%)$ presented with CP either isolated (8/85 patients, $9.4 \%)$ or associated with epilepsy and mental retardation $(13 / 85,15.3 \%)$. Mental retardation was present in 27 patients $(31.7 \%)$; in 8 of these $(9.4 \%)$ this was isolated.

\section{Development of Subsequent Epilepsy}

At the last follow-up, 15 infants presented with epilepsy, making the cumulative incidence of postneonatal epilepsy in these children with antecedents of neonatal seizures $17.6 \%$. In $60 \%$ the onset of epilepsy was in the neonatal period, whereas in $13.3 \%$ the onset occurred in the first 3 mo of life or the first year, and after the first year of life in the remaining $26.6 \%$. Statistical analysis showed that EEG background activity, US, and efficacy of the anticonvulsant therapy were independent variables predictive of a higher risk of subsequent epilepsy (Tables 1 and 2). Epilepsy-free survival data are presented in Figure 1.

Regarding nosological aspects, all of our patients developed symptomatic localization-related epilepsy with focal motor seizures and secondary generalization. Four infants also presented an electro-clinical pattern consistent with West syndrome. Moreover, all but two of the patients with epilepsy had CP and mental retardation (86.6\%); of these, $73.3 \%$ had a spastic quadriplegia. Table 3 shows the US and electro-clinical features as well as the outcome of the epileptic patients at $7 \mathrm{y}$ of age.

\section{Refractoriness to Antiepileptic Drug Treatment}

In our sample only one of 18 newborns (5.5\%) who were refractory to anticonvulsants had a completely normal ultrasound scan and 5 newborns (27\%) were diagnosed with a mild intraventricular hemorrhage or transient periventricular echodensities. Nine of the 18 refractory patients subsequently developed epilepsy. The coexistence in the majority of our patients of brain damage and drug-resistant seizures (12/18) did not allow us to disentangle which was the cause of the increased incidence of epilepsy in this subgroup.

\section{DISCUSSION}

Neonatal seizures are often thought to be an epiphenomenon of the underlying brain damage and it is the latter that usually leads to an adverse outcome. According to Lilienfeld and Pasamanick, it is the "brain damage incurred during the prenatal and perinatal periods as a result of abnormalities during these periods" that leads to "a gradient of injury extending from fetal and neonatal death through CP, epilepsy, behavior disorder, and mental retardation (9)". In our study, we evaluated whether neonatal seizures that occurred in our sample could be considered a risk factor for epileptogenesis. The risk for developing epilepsy in childhood in patients with history of neonatal seizures is reported as greater than $50 \%$ as compared with a $0.5 \%$ risk for the general pediatric population (2). However, this rate has significant variability in the literature partly due to variability in inclusion criteria adopted by different studies. In addition, some authors only consider 
full-term newborns, whereas others include both full-term and preterm newborns. A 56\% rate of epilepsy has been reported in newborns with video-EEG-confirmed seizures that were followed-up to a mean postnatal age of 31 mo (7), whereas only $17.6 \%$ of the newborns recruited to our study

Table 2. Multivariate analysis: risk factors for postneonatal epilepsy

\begin{tabular}{lccc}
\hline Variable & OR & $95 \% \mathrm{Cl}$ & $P$ \\
\hline Efficacy of therapy & & & $<0.01$ \\
Good response & 1.00 & & \\
Partial response & 10.7 & $1.1-103.5$ & 0.04 \\
No response & 38.1 & $3.7-383.2$ & $<0.01$ \\
\hline
\end{tabular}

$\mathrm{Cl}$, confidence interval; $\mathrm{OR}$, odds ratio.
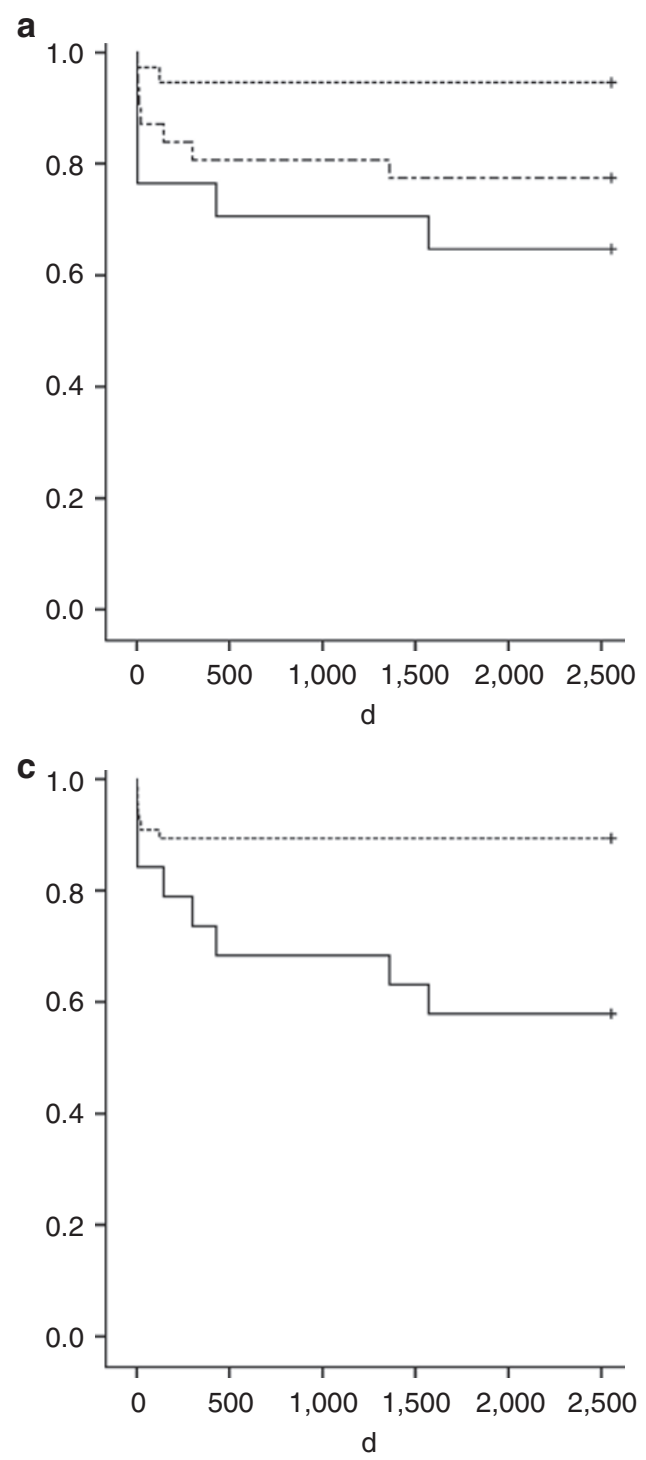

developed epilepsy later in life. However, even with reported variability in the incidence across different studies, early seizures seem to be predictors of epilepsy following brain injuries, although it is not clear if this effect is independent of the severity of the injury. Remote symptomatic seizures are thought to be the consequences of chronic changes in neural networks favoring excitation. In fact, it is reported that about $20 \%$ of survivors with neonatal seizures have one or more seizures by $7 \mathrm{y}$ of age, with most occurring during the first year of life (10). Because neonatal seizures seem to contribute to the development of postneonatal epilepsy, a careful individual assessment of the potential risk factors in these newborns is required. In our study, the response to antiepileptic drugs (AEDs), the presence of status epilepticus (SE), severe

b

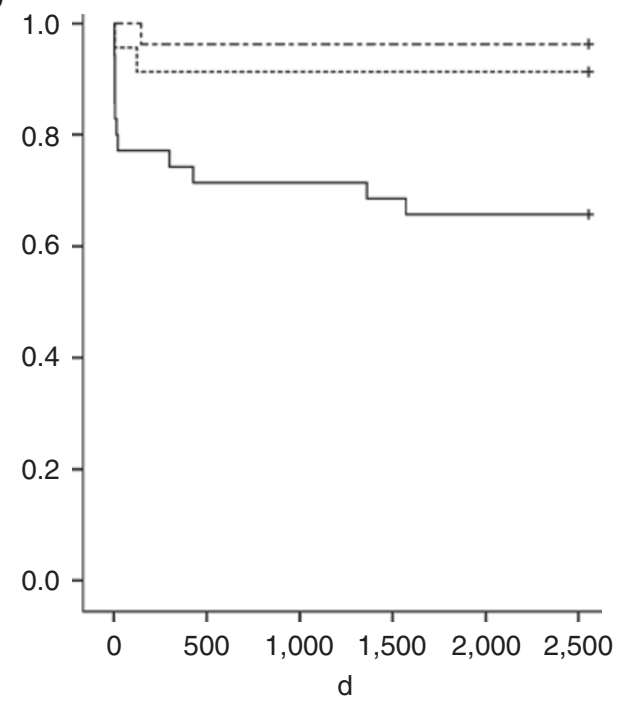

d

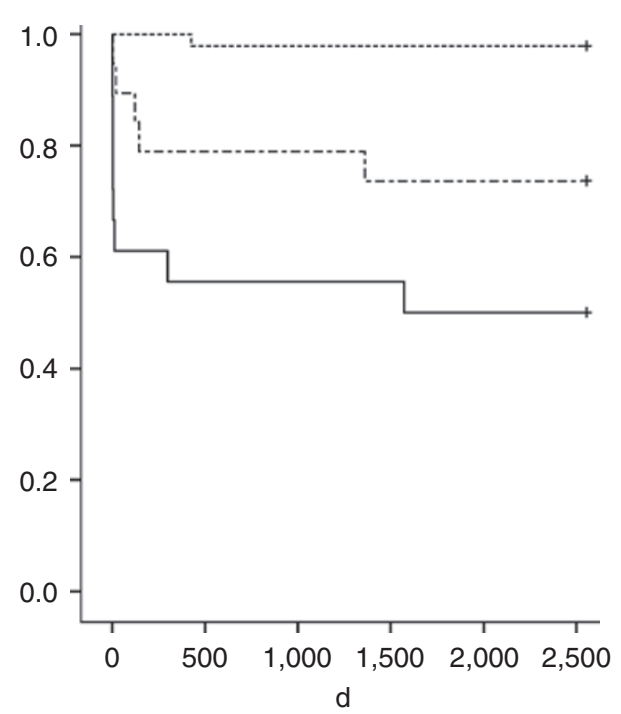

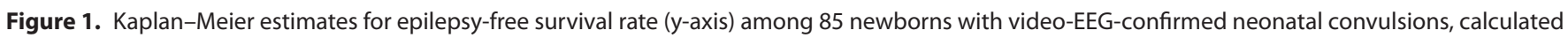
over the minimum follow-up period of 7 y $(2,555 \mathrm{~d})$. (a) Patients with a normal or mildly abnormal background EEG, dashed line $(n=37)$; moderately abnormal EEG, dash-dot line $(n=31)$; or severely abnormal EEG, solid line $(n=17)$. (b) Newborns with normal US brain scan, dash-dot line ( $n=23)$; US abnormalities grade II, dashed line $(n=27)$; and US abnormalities grade III, solid line $(n=35)$. (c) Patients with status epilepticus, solid line ( $n=66)$; and patients without, dashed line $(n=19)$. (d) Patients in which drug treatment was effective on convulsions, dashed line ( $n=48)$; patients with partial response, dash-dot line $(n=19)$; and patients with refractoriness, solid line $(n=18)$. EEG, electroencephalogram; US, ultrasound. 
Table 3. US and electroclinical features of subjects with postneonatal epilepsy

\begin{tabular}{|c|c|c|c|c|c|c|}
\hline $\mathrm{Pt}$ & GA wk & US findings & EEG findings & West syndrome & Seizures type & Outcome \\
\hline 1 & 35 & Multicystic encephalopathy & $\begin{array}{l}\text { Multiple foci, more evident } \\
\text { on right posterior regions }\end{array}$ & + & $\begin{array}{l}\text { Class } 2 \text { CPS, } \\
\text { PSSG }\end{array}$ & $\begin{array}{l}\text { Spastic quadriplegia, } \\
\text { DD, epilepsy }\end{array}$ \\
\hline 3 & 30.5 & $\begin{array}{l}\text { IV/IP hemorrhage, hydrocephalus, } \\
\text { bilateral porencephalic cysts }\end{array}$ & $\begin{array}{l}\text { Hypsarrhythmia, then } \\
\text { multiple foci more active } \\
\text { on the left centrotemporal } \\
\text { regions }\end{array}$ & + & $\begin{array}{l}\text { Class } 2 \text { CPS, } \\
\text { PSSG }\end{array}$ & $\begin{array}{l}\text { Spastic quadriplegia, } \\
\text { DD, epilepsy }\end{array}$ \\
\hline 4 & 24 & $\begin{array}{l}\text { IV/IP hemorrhage, ventricular } \\
\text { dilatation }\end{array}$ & Left parieto-occipital focus & & Class 1 PSSG & $\begin{array}{l}\text { Right hemiplegia, } \\
\text { DD, epilepsy }\end{array}$ \\
\hline 5 & 28 & $\begin{array}{l}\text { IV/IP hemorrhage, hydrocephalus, } \\
\text { right porencephalic cyst }\end{array}$ & $\begin{array}{l}\text { Focus on the right posterior } \\
\text { regions }\end{array}$ & & $\begin{array}{l}\text { Class } 3 \text { CPS, } \\
\text { PSSG }\end{array}$ & $\begin{array}{l}\text { Spastic quadriplegia, } \\
\text { DD, epilepsy }\end{array}$ \\
\hline 6 & 29 & $\begin{array}{l}\text { Cystic PVL, ventricular dilatation, } \\
\text { atrophy }\end{array}$ & $\begin{array}{l}\text { Hypsarrhythmia, then } \\
\text { multiple foci more active on } \\
\text { the left posterior regions }\end{array}$ & + & $\begin{array}{l}\text { Class } 2 \text { CPS, } \\
\text { PSSG }\end{array}$ & $\begin{array}{l}\text { Spastic quadriplegia, } \\
\text { DD, epilepsy }\end{array}$ \\
\hline 8 & 40 & Microcephaly, brain atrophy & Multiple foci & & Class 4 PSSG & $\begin{array}{l}\text { Spastic quadriplegia, } \\
\text { DD, epilepsy }\end{array}$ \\
\hline 9 & 37 & IV/IP hemorrhage & Multiple foci & & Class 1 CPS & $\begin{array}{l}\text { Spastic quadriplegia, } \\
\text { DD, epilepsy }\end{array}$ \\
\hline 10 & 41 & Cystic PVL, brain atrophy & Multiple foci & & Class 2TS & $\begin{array}{l}\text { Spastic quadriplegia, } \\
\text { DD, epilepsy }\end{array}$ \\
\hline 11 & 42 & $\begin{array}{l}\text { Cystic PVL ventricular dilatation, brain } \\
\text { atrophy }\end{array}$ & Multiple foci & & Class 4 CPS & $\begin{array}{l}\text { Spastic quadriplegia, } \\
\text { DD, epilepsy }\end{array}$ \\
\hline 12 & 40 & IV/IP hemorrhage & Multiple foci & + & Class 4 PSSG & $\begin{array}{l}\text { Left hemiplegia, DD, } \\
\text { epilepsy }\end{array}$ \\
\hline
\end{tabular}

CPS, complex partial seizures; DD, developmental delay; EEG, electroencephalogram; GA, gestational age; IV/IP, intraventricular/intraparenchymal hemorrhage; PSSG, partial seizures with secondary generalization; PVL, periventricular leukomalacia; TS, tonic seizures; US, ultrasound.

abnormal background EEG activity, and severely abnormal cerebral US scan findings seem to be predictors of postneonatal epilepsy.

Newborns who fail to respond to anticonvulsant treatment have up to a fourfold increased risk of developing epilepsy $(11,12)$. Furthermore, these patients had more severe cerebral damage, which could independently lead to more prolonged and untreatable acute seizures and subsequent development of epilepsy. Whether or not the underlying etiology accounts for both the poor seizure control and the adverse outcome is still a matter of debate. Some authors consider the underlying etiology and not the seizures to be the main factor responsible for subsequent epilepsy (13). However, animal studies highlight how recurrent neonatal seizures may impair neurogenesis in the dentate gyrus (14) and lead to a persistent enhancement of neocortical excitability with increased susceptibility to seizure generation (15).

Capitalizing on the fact that all newborns who have neonatal seizures at our NICU are EEG-monitored, we observed that $27.1 \%(13 / 48)$ of those with severe abnormalities in the background EEG activity developed epilepsy, accounting for $86 \%$ of all epileptic patients. Some studies suggest that background EEG activity is a predictor of epilepsy, although usually related to the neurodevelopmental outcome, and more recently the presence of persistent background abnormalities in sequential EEG recordings was related to an increased risk for epilepsy (relative risk $=1.8$; ref. 16). Increasing availability of amplitude-integrated EEG in monitoring neonates with seizures $(11,17)$ and differences in ascertainment (prospective vs. retrospective studies) might account for some of the differences in results $(7,18)$. A rate of $9.5 \%$ of postneonatal epilepsy has been reported in studies using amplitudeintegrated EEG (11) and higher rates were seen in hospitalbased studies where the seizures were EEG-confirmed (41.4 to $56 \%$; refs. 7,16). Furthermore, rates of epilepsy in the surviving patients varying between 18 and $27 \%$ are seen in large population studies with clinically identified seizures and long follow-up $(3,18)$. 
The duration of the seizures also seems to be a predictor of epilepsy. In our study, of the 19 patients with SE, 8 (42\%) developed epilepsy. Often SE occurs in the context of brain insults that are in themselves risk factors for epilepsy. Animal models of SE are often used to understand epileptogenesis; however, the real influence of SE in human epilepsy is difficult to establish. In a retrospective study, a history of SE at onset of the seizures increased the incidence of later unprovoked seizures to $41 \%$ compared with $13 \%$ in those without SE (19). The etiology of acute SE has been reported as responsible for increased risk of late seizures with those with anoxic insults having the highest relative risk (18.8 ref. 19). Furthermore, our study suggests that the more severe the brain damage seen on US, the higher the risk of developing postneonatal epilepsy. These data suggest a synergistic effect of the underlying brain disorder and SE for the development of epilepsy, such that when seizures are particularly prolonged and/or are coupled with structural brain damage, subsequent epilepsy may occur (20). This is also indirectly corroborated by recent clinical studies that reported that larger stroke size is associated with higher risk of later seizures (21), and patients with neonatal encephalopathy who developed severe brain damage are more likely to develop epilepsy as compared with those with mild to moderate brain injuries; furthermore, SE was independently associated with epilepsy (hazard ratio $=17.3$ ) in the multivariate analysis adjusted for degree of encephalopathy and severe/near-total brain injury (22).

Although cerebral magnetic resonance imaging provides high-resolution images especially for detecting subtle white matter injury, we used cerebral US in close temporal relationship with onset of neonatal seizures as this is still the most frequently used brain imaging technique in the vulnerable newborn in the NICU due to its safety, noninvasiveness, and accessibility at bedside (23). Moreover, US is an highly sensitive method for detecting germinal-layer hemorrhage, cystic changes, periventricular leukomalacia, and intraventricular hemorrhage, which are all known to be risk factors for an adverse outcome (23). In our study, we could not find any association between the type of etiology and postneonatal epilepsy. In a population-based cohort study, the highest relative risks for childhood epilepsy were associated with eclampsia and neonatal seizures regardless of cause (24).

The frequency of epilepsy was similar in full-term (18.1\%) and preterm (17.1\%) newborns. In our study, data in preterm newborns are similar to those reported in the literature. The frequency in full-term newborns is somewhat lower compared with that of Scher et al. (25), who reported a rate of postneonatal epilepsy of $30 \%$ in their full-term newborns in a hospital-based study with EEG-confirmed seizures. Their study includes a higher percentage of cerebral infarcts (77\%) and of newborns at high risk of adverse outcome (such as outborn patients, those with brain malformations, and those with inherited metabolic diseases: all of these conditions were excluded from our study). These considerations suggests that difficulties in comparing results from different studies might be due to a combination of factors, including therapeutic advances occurring in the NICU in recent years and differences in inclusion criteria. In all but two of our children, epilepsy was associated with developmental delay and CP. This confirms that patients with acute symptomatic neonatal seizures are at high risk of multiple neurodevelopmental disabilities (26).

Individuals with neurological abnormalities and developmental delay are known to be at higher risk of febrile seizures (27). Moreover, febrile seizures are reported to be associated with an increased risk of epilepsy, which is particularly high for persons with CP, low Apgar scores, or a family history of epilepsy (28). In two of the three patients with onset of epilepsy after the first year of life, this was preceded by a febrile SE. The effect of febrile convulsive SE on the brains of our patients might, therefore, have resulted in an additive acute brain injury and therefore contributed to the development of epilepsy.

A wide range of studies conducted on different developmental models of epilepsy suggest that epileptogenesis early in life has unique features (29). In $60 \%$ of the studied patients, the onset of epilepsy was in the neonatal period (9/15) in the form of symptomatic epilepsy with focal seizures, 4 patients (26.6\%) developed West syndrome, and in 3 patients onset was after the first year of life. One of the explanations might be in the severity of the cerebral damage in our group of patients. In only six patients, a brief silent period preceded the development of epilepsy. Such time delay might have allowed an abnormal synaptic reorganization and in turn epileptic neuronal circuits. The frequency of West syndrome was lower than in a previous report (30).

Whatever the specific mechanisms of injury, the main pathological features include either massive cell death that starts the epileptogenesis process, or repetitive and prolonged seizures that may alter the developing brain early in life to create epileptic neuronal circuits $(29,31)$. Finally, our data confirm that newborns with neonatal seizures deserve special care because they are at higher risk of developing postneonatal epilepsy and require specialist care.

\section{METHODS AND PATIENTS}

This study was conducted on newborns with neonatal seizures who were consecutively admitted to the NICU of the University Hospital of Parma between January 1999 and December 2004. We set the following inclusion criteria: (i) repeated neonatal EEG-confirmed seizures; (ii) the first video-EEG with ictal activity performed before starting antiepileptic therapy; (iii) more than one video-EEG performed during the neonatal period; (iv) more than one US examination performed up to term age and at least one computed tomography and/or magnetic resonance imaging examination obtained in the first year of life in the surviving patients; and (v) neurological and EEG follow-up to at least $7 \mathrm{y}$ of age.

Neonates with congenital malformations or inherited metabolic diseases were excluded from this study. Video-EEG data were available as part of the routine assessment and care of all newborns at high risk of having seizures based on predisposing factors such as birth asphyxia, sepsis, meningitis, metabolic disorders, malformations, intraventricular hemorrhage, or periventricular leukomalacia on brain US, or who presented with clinical signs suggestive of seizures. 


\section{Clinical Findings}

The following variables were collected: natural childbirth or cesarean section, singleton versus multiple gestation, kind of delivery, gender, GA, birth weight, Apgar score at the first and fifth minute, and need for cardiopulmonary resuscitation.

Based on GA, our sample was divided into four subgroups; GA $\geq$ $37 \mathrm{wk}, \mathrm{GA}=34-36 \mathrm{wk}, \mathrm{GA}=29-33 \mathrm{wk}$, and GA $\leq 28 \mathrm{wk}$.

Birth weight was ranked in three categories: $\geq 1,500 \mathrm{~g}$ (low birth weight), between 1,000 and $1,499 \mathrm{~g}$ (very low birth weight), $<1,000 \mathrm{~g}$ (extremely low birth weight).

Apgar score at the first and fifth minutes was ranked as follows: $\leq 3$; between 4 and $7 ; \geq 8$.

The need for and the kind of resuscitation was separated into the following four categories: (i) routine assistance, (ii) need for oxygen supply, (iii) intermittent positive-pressure ventilation, (iv) continuous positive-pressure ventilation/endotracheal intubation/cardiopulmonary resuscitation.

The neurological examinations performed at the beginning of the neonatal seizures were classified as follows: (i) normal: with normal muscle tone, active muscle movements present, normal alertness for age; (ii) moderately abnormal: with hypotonia/hypertonia, decreased active muscle movements, and lethargy; and (iii) severely abnormal: meaning flaccid, inactive, and/or coma (32).

Clinical seizures without EEG correlates were not considered. Time of seizure onset was divided into periods before or after the first 24 or $48 \mathrm{~h}$ of life. Based on seizure semiology, patients were classified as having one or multiple seizure types (33). The occurrence of SE (34) was also coded as a variable.

The current therapeutic approach in our unit prescribes an intravenous bolus of phenobarbital at a dose of $20 \mathrm{mg} / \mathrm{kg}$, repeated once if seizures persist, followed by intravenous administration of phenytoin at a loading dose of $20 \mathrm{mg} / \mathrm{kg}$ at a rate of no more than $1 \mathrm{mg} /$ $\mathrm{kg} / \mathrm{min}$ should seizures persist. When this treatment failed to control the seizure, our third-line anticonvulsant treatment consisted of an intravenous bolus of midazolam at $0.15 \mathrm{mg} / \mathrm{kg}$ followed by continuous intravenous infusion at $1 \mu \mathrm{g} / \mathrm{kg} / \mathrm{min}$, increased by $1 \mu \mathrm{g} /$ $\mathrm{kg} / \mathrm{min}$ every $15 \mathrm{~min}$. Response to anticonvulsant therapy was classified as good if seizures stopped after the use of the first AEDs; partial when seizures stopped after the use of the second AED, and no response when they persisted or recurred after the use of the second AED.

\section{Electrophysiological and Neuroimaging Assessment}

Polygraphic EEGs were obtained at the bedside in the NICU. Depending on the head size of the infants, 10 or 21 scalp electrodes were applied according to the 10-20 International System. Electrocardiogram, lateral eye movements, chin electromyographic activity, and abdominal respiration were the other most frequently monitored physiological variables; an EEG technician was present throughout the entire recording. Recordings continued until a complete cycle of wakefulness, quiet, and active sleep was obtained. However, when the state changes were not clearly distinguishable, the recording continued for at least $60 \mathrm{~min}$. Standardized age-dependent criteria (35) were applied to assess EEG background activity, which was scored as:

1. Normal or mildly abnormal: excess sharp activity, absence or decreased frequency of normal patterns, excessively long lowvoltage periods, or overall slightly decreased voltage;

2. Moderately abnormal: asymmetries in voltage or frequencies, asynchrony for age;

3. Severely abnormal: isoelectric or low-voltage invariant activity, burst-suppression pattern, permanent discontinuous activity.

The ictal EEG discharges were selected according to the following criteria: (i) clear beginning and end, (ii) lasting more than $10 \mathrm{~s}$, and (iii) evolution in frequency and morphology. Any behavioral change and specific clinical correlates were noted.

In all infants, we performed real-time cerebral US in the first $72 \mathrm{~h}$ of life and repeated the procedure in the second week of life by the 14th postnatal day and at 40-wk postconceptional age. Abnormalities such as intracranial hemorrhage, parenchymal echodensities, and hydrocephalus and brain malformations were recorded and classified, with increasing scores reflecting more severe damage. Computed tomography or magnetic resonance imaging was available for every patient and the data were used in the analysis only if discordant from the US findings.

\section{Outcome Measures}

Neurodevelopmental outcome was assessed at 44-wk postconceptional age, 1 mo after hospital discharge, at the corrected age of 3 , $6,9,12,18$, and $24 \mathrm{mo}$ and every $6 \mathrm{mo}$ afterwards up to the age of $7 \mathrm{y}$. The oldest patients continued to be followed up every 6 mo or according to clinical needs. Neuromotor assessment was based on Amiel-Tison and Dubowitz's neurological examination $(32,36)$. Developmental quotient was measured using Griffiths' Mental Developmental Scale (37). Results were classified as normal when the developmental quotient was 80 or above and as abnormal when it was below 80 . CP was diagnosed in the presence of a qualitative motor disorder due to nonprogressive interference with development of the brain occurring before the growth of the central nervous system is complete (38). It was classified according to topography and the nature of the motor disorder (38). Neurodevelopmental outcome was classified as favorable in the presence of normal neurological development or mild muscle tone and reflex abnormalities. Adverse outcome was defined as the presence of CP, developmental delay, epilepsy, or death. Infants were considered as having epilepsy when unprovoked, recurring epileptic seizures either occurred in the neonatal period persisting beyond the third month of corrected age and it was impracticable to taper off the antiepileptic therapy or had an onset after the neonatal period. We defined the neonatal period up to 44 completed weeks' postconceptional age for preterm infants born at $\leq 36$ wk of GA. Epileptic spikes/sharps waves in the routine EEG and need for chronic anticonvulsant therapy had to be present. The types of seizures and epileptic syndromes were determined based on the proposed classification by the International League Against Epilepsy (39). Epilepsy was graded according to a modified Engel classification (40). All the measured clinical variables were investigated in relation to the development of postneonatal epilepsy.

\section{Statistical Analysis}

The Student's $t$ test for unpaired data was used to compare means of continuous variables. Nominal data were analyzed by means of the $\chi^{2}$ test or Fisher's exact test as appropriate. OR was calculated using a univariate logistic regression model to determine which independent variable(s) were related to epilepsy. Variables with a $P$ value $<0.05$ and with an $\mathrm{OR}>1$ on univariate analysis were included in a multiple logistic regression analysis. We used multivariate analysis to evaluate which independent variable/s were related to postneonatal epilepsy. To test the association of predictors with time to onset of epilepsy and the equality of survival distributions for the different levels of the predictors (EEG, US, SE, and efficacy of therapy) the log-rank (Mantel-Cox) statistics were computed. The Kaplan-Meier estimator was used to compute and display graphically the survival curves.

For the statistical analysis, etiologies were grouped into the following three categories: hypoxic-ischemic encephalopathy, cerebral hemorrhage, and others. In all instances, a $P$ value less than 0.05 was accepted as significant. Statistical analysis was performed using the Statistical Package for the Social Sciences (Version 19.0.0; IBM SPSS Statistics, Chicago, IL, 2010).

The study was approved by the University of Parma Ethics Review Board. In accordance with current practice at our institution, informed consent was obtained before recruitment to the study and a form was signed by the parents of the patients to approve the use of patient information or material for scientific purposes; the informed consent forms were placed in the patient's hospital chart.

\section{STATEMENT OF FINANCIAL SUPPORT}

No extramural financial assistance was received to support this study. 


\section{REREFENCES}

1. Volpe JJ. Neurology of the Newborn. Philadelphia, PA: Saunders, 2008:178-214.

2. Scher MS. Neonatal seizure classification: a fetal perspective concerning childhood epilepsy. Epilepsy Res 2006;70:Suppl 1:S41-57.

3. Ronen GM, Buckley D, Penney S, Streiner DL. Long-term prognosis in children with neonatal seizures: a population-based study. Neurology 2007;69:1816-22.

4. Mizrahi EM, Watanabe K. Symptomatic neonatal seizures. In: Roger J, Bureau M, Dravet C, Genton P, Tassinari CA, Wolf P, eds. Epileptic Syndromes in Infancy, Childhood and Adolescence. Montrouge, France: John Libbey Eurotext, 2005:17-38.

5. Jensen FE. Developmental factors regulating susceptibility to perinatal brain injury and seizures. Curr Opin Pediatr 2006;18:628-33.

6. Williams PA, Dou P, Dudek FE. Epilepsy and synaptic reorganization in a perinatal rat model of hypoxia-ischemia. Epilepsia 2004;45:1210-8.

7. Clancy RR, Legido A. Postnatal epilepsy after EEG-confirmed neonatal seizures. Epilepsia 1991;32:69-76.

8. Tekgul H, Gauvreau K, Soul J, et al. The current etiologic profile and neurodevelopmental outcome of seizures in term newborn infants. Pediatrics 2006;117:1270-80.

9. Lilienfeld AM, Pasamanick B. The association of maternal and fetal factors with the development of cerebral palsy and epilepsy. Am J Obstet Gynecol 1955;70:93-101.

10. Ellemberg JH, Hirts DG, Nelson KB. Age at onset of seizures in young children. Ann Neurol 1984;15:127-34.

11. Toet MC, Groenendaal F, Osredkar D, van Huffelen AC, de Vries LS. Postneonatal epilepsy following amplitude-integrated EEG-detected neonatal seizures. Pediatr Neurol 2005;32:241-7.

12. Garfinkle J, Shevell MI. Cerebral palsy, developmental delay, and epilepsy after neonatal seizures. Pediatr Neurol 2011;44:88-96.

13. Berg AT, Shinnar S. Prolonged anticonvulsant use and refractoriness to treatment was predictive of epilepsy. J Clin Neurophysiol 1997;14:102-10.

14. McCabe BK, Silveira DC, Cilio MR, et al. Reduced neurogenesis after neonatal seizures. J Neurosci 2001;21:2094-103.

15. Isaeva E, Isaev D, Savrasova A, Khazipov R, Holmes GL. Recurrent neonatal seizures result in long-term increases in neuronal network excitability in the rat neocortex. Eur J Neurosci 2010;31:1446-55.

16. Khan RL, Nunes ML, Garcias da Silva LF, da Costa JC. Predictive value of sequential electroencephalogram (EEG) in neonates with seizures and its relation to neurological outcome. J Child Neurol 2008;23: 144-50.

17. van Rooij LG, de Vries LS, Handryastuti S, et al. Neurodevelopmental outcome in term infants with status epilepticus detected with amplitudeintegrated electroencephalography. Pediatrics 2007;120:e354-63.

18. Holden KR, Mellits ED, Freeman JM. Neonatal seizures. I. Correlation of prenatal and perinatal events with outcomes. Pediatrics 1982;70:165-76

19. Hesdorffer DC, Logroscino G, Cascino G, Annegers JF, Hauser WA. Risk of unprovoked seizure after acute symptomatic seizure: effect of status epilepticus. Ann Neurol 1998;44:908-12.

20. Herman ST. Epilepsy after brain insult: targeting epileptogenesis. Neurology 2002;59(9 Suppl 5):S21-6.
21. Wusthoff CJ, Kessler SK, Vossough A, et al. Risk of later seizure after perinatal arterial ischemic stroke: a prospective cohort study. Pediatrics 2011;127:e1550-7.

22. Glass HC, Hong KJ, Rogers EE, et al. Risk factors for epilepsy in children with neonatal encephalopathy. Pediatr Res 2011;70:535-40.

23. Vollmer B, Roth S, Baudin J, Stewart AL, Neville BG, Wyatt JS. Predictors of long-term outcome in very preterm infants: gestational age versus neonatal cranial ultrasound. Pediatrics 2003;112:1108-14.

24. Whitehead E, Dodds L, Joseph KS, et al. Relation of pregnancy and neonatal factors to subsequent development of childhood epilepsy: a population-based cohort study. Pediatrics 2006;117:1298-306.

25. Scher MS, Aso K, Beggarly ME, Hamid MY, Steppe DA, Painter MJ Electrographic seizures in preterm and full-term neonates: clinical correlates, associated brain lesions, and risk for neurologic sequelae. Pediatrics 1993;91:128-34.

26. Garfinkle J, Shevell MI. Predictors of outcome in term infants with neonatal seizures subsequent to intrapartum asphyxia. J Child Neurol 2011;26:453-9.

27. Bethune P, Gordon K, Dooley J, Camfield C, Camfield P. Which child will have a febrile seizure? Am J Dis Child 1993;147:35-9.

28. Vestergaard M, Pedersen CB, Sidenius P, Olsen J, Christensen J. The longterm risk of epilepsy after febrile seizures in susceptible subgroups. Am J Epidemiol 2007;165:911-8.

29. Bender RA, Baram TZ. Epileptogenesis in the developing brain: what can we learn from animal models? Epilepsia 2007;48:Suppl 5:2-6.

30. Watanabe K, Kuroyanagi M, Hara K, Miyazaki S. Neonatal seizures and subsequent epilepsy. Brain Dev 1982;4:341-6.

31. Dudek FE, Ekstrand JJ, Staley KJ. Is neuronal death necessary for acquired epileptogenesis in the immature brain? Epilepsy Curr 2010;10:95-9.

32. Dubowitz L, Dubowitz V, Mercuri E. The neurological assessment of the preterm and full-term newborn infant. Clinics in Developmental Medicine, 2nd ed, 148. London: McKeith Press, 1999.

33. Lombroso CT. Neonatal seizures: a clinician's overview. Brain Dev 1996;18:1-28

34. Pisani F, Cerminara C, Fusco C, Sisti L. Neonatal status epilepticus vs recurrent neonatal seizures: clinical findings and outcome. Neurology 2007;69:2177-85.

35. Holmes GL, Lombroso CT. Prognostic value of background patterns in the neonatal EEG. J Clin Neurophysiol 1993;10:323-52.

36. Amiel-Tison C, Grenier A. Neurological Assessment During the First Year of Life. New York: Oxford University Press, 1986.

37. Griffiths R. The abilities of Young Children. London, UK: Child Development Research Centre, 1970.

38. Shapiro BK. Cerebral palsy: A reconceptualization of the spectrum. J Pediatr 2004;145(2 Suppl):S3-7.

39. Engel J Jr; International League Against Epilepsy (ILAE). A proposed diagnostic scheme for people with epileptic seizures and with epilepsy: report of the ILAE Task Force on Classification and Terminology. Epilepsia 2001;42:796-803.

40. Golomb MR, Garg BP, Carvalho KS, Johnson CS, Williams LS. Perinatal stroke and the risk of developing childhood epilepsy. J Pediatr 2007;151:409-13, 413.e1-2. 